\title{
CHANGING THE WORLD, ONE WORD AT A TIME
}

\author{
The struggles of higher education and \\ communicative action in a capitalist world
}

\section{Author: Sergio Calderón-Harker}

Abstract Debates within critical educational theory and its relation to capitalism have often been heavily influenced by the tradition of critical social theory. For instance, Jürgen Habermas' (1984; 1987) communicative action approach has proven to be a valuable theory that combines both analytical considerations regarding the conflict between the 'lifeworld' and 'system', and a decisively normative theory for deliberative and democratic discourse. However, Habermas' communicative action is not without problems, as a critical linguistic approach may prove. As such, in this paper I attempt to analyse the issues of communicative action in the context of anti-capitalist discourse and debate within and about higher education. To do this, I first outline Habermas' (1984) and Fleming's (2008) theories on the colonization of higher education, followed by a critique by means of Wittgenstein's (1968) philosophy of language. As such, I argue that, in order to decolonize higher education from the logic of capital, we must reflect upon the language-games used when speaking about education. 


\section{Introduction}

Throughout the history of mankind, thinkers, theorists, and philosophers have argued that we find ourselves in a state of crisis, of constant conflict and transformation. To resolve this crisis, different philosophers prescribe different forms of analysis and subsequent modes of action. Karl Marx, for instance, analysed the history of the world as that of class struggle, suggesting that in order to alleviate the crises inherent in a capitalist world, a unified revolt must take place to create a new social order (Marx \& Engels, 1969, p. 132). From this Marxist tradition, Jürgen Habermas (1987) provides his own synthesized analysis of our current capitalist reality, arguing that societal well-being is determined by a critical balance between the so-called lifeworld and system. Capitalist modernity, according to Habermas (1987, p.187), has allowed for the system to colonize the lifeworld. The latter, which serves as a stage for the creation and sustenance of cultural traditions and social integration, has been outweighed by the ever-growing imperatives from the system; dissimilarly, this sphere encompasses actions and relations characterized by a productive and economic nature. Productivity, profitability, and efficiency, for instance, have trumped the crucial significance of meaning-making and self-expression in the public sphere (Fleming, 2008; Habermas, 1987; Sloan, 1999).

Utilising Habermas' themes and analytical framework, Ted Fleming (2008) attempts to examine the current crisis of higher education. As such, he argues that a critical higher education is necessary for a democratic society. This type of education, however, has come into threat by the movement of system imperatives into the educational sphere, a space formerly distinguished by its capacity to bring into life and set in motion a plurality of lifeworld activities. Employing Habermas' (1984) normative conjectures, Fleming (2008) suggests that to resolve the current crisis, educational actors must create spaces for communicative action that will allow for critical discourse to be present in higher education. Nonetheless, the struggle for communicative action spaces in our current capitalist world may be hindered by major discursive forces that transcend the very act of deliberation. The question that must be posed, then, is: how can we realize the ideal of critical higher education in a world shaped by the colonization of the lifeworld by capitalist modernity?

In this paper, I argue that if we want to strive for a critical higher education, we must move beyond creating spaces for communicative action, and reflect upon the language games that we use when we speak about education. Only by changing the precise words, linguistic expressions, and conjectures utilized in the educational context can we create a truly critical and emancipatory edu- 
cation. The ideal set forth by higher education may therefore be achieved by uprooting the educational language-games from system imperatives and the intricate logic of capital. To argue this, I first explain Habermas' (1984; 1987) theoretical framework and normative conjectures, exploring his lifeworld and system theory as well as his claim in support of communicative action. Following this, I depict the current problem of higher education through Habermasian lenses as outlined by Fleming (2008). Third, I explain Ludwig Wittgenstein's (1968) linguistic theory, finally discussing the challenge posed to the prescription of communicative action by the language-games of the system in the context of our capitalist reality.

\section{Habermas' lifeworld and system, and the promise of communicative action}

To outline his prescription of communicative action as an emancipatory and democratic discursive tool, Habermas (1987) first constructs an analytical framework through the notions of the lifeworld and system. By lifeworld, Habermas understands a background context of macro-level social processes that create and determine meaning: the reproduction and maintenance of cultural traditions and knowledge, personal and collective identity development and creation, as well as communicative and practical action aimed at the resolution of ethical and normative disputes (p. 119). Meanwhile, the system comprises activities related to productive operations essential for physical survival, encompassing the economy and labour practices (p. 155). In an ideal situation, where a critical balance between these two aspects is the norm, it is the social processes and meaning created in the lifeworld that determine and guide the functioning of the system (Sloan, 1999). For instance, if a community in a large city creates the collective meaning that their neighbourhood must be free of religious buildings, this would outweigh someone's desire to build a chapel, synagogue, or mosque in order to create more jobs for the community. Habermas (1987) argues that this is not the case under capitalist modernity, which has enabled processes that allow for the preference of economic and productive interests over meaning-making and personal and collective needs.

Moreover, by disrupting the critical balance, capitalist modernization has led to the so-called colonization of the lifeworld. This refers to the phenomenon through which the system invades and occupies the lifeworld, interfering in meaning-making activities among individuals and communities on a daily basis (Habermas, 1987, p. 154). In practical terms this means that system concerns, 
such as efficiency, competitiveness, growth, and profitability, trump and displace lifeworld interests such as social norms, cultural meanings, morals and self-expression (Bolton, 2005; Sloan, 1999). In the case of the aforementioned community, capitalist reality would render the need for jobs and economic growth more important than communal values: the amount of capital accumulation produced by the project of building a religious establishment would outweigh the community's strict secular identity. This embodies what sociologist Max Weber described as zweckrationalität or instrumental rationality: the ability for the logic of capital to permeate into the thinking of individuals and thereby the public sphere (Sloan, 1999). In turn, this allows for the social order to sustain system needs in terms of economic efficiency and growth in place of cultural knowledge and values, solidarity, and personal identity (Bolton, 2005; Habermas, 1987). In this colonization, the logic of capital dictates and shapes the functioning of every day society, presenting itself as the underlying ideological form of system rationality.

In the face of the lifeworld colonization, Habermas (1984) proposes the creation of spaces for communicative action as an attempt to 'fix' the critical balance. Most importantly, communicative action offers a public and democratic discourse, with the aim of allowing for deliberation by members who stand on equal terms to one another. This is particularly characterized by actions of members being coordinated with the purpose of reaching inter-subjective understanding (p. 101). In addition, communicative action occurs in social situations of dialogue and deliberation where participants are not dominated by their own interest to succeed (p. 86). Instead, due to common understanding of situations, based on the premise that people may act rationally and in a disinterested manner, participants may reach a consensus in terms of the community's needs, finally making these their own (Bolton, 2005; Fleming, 2008). For instance, in the example of the community attempting to reject the construction of a religious building in their neighbourhood, communicative action would allow for members to come forth and, through a process of deliberation and rationalization, come to a consensus that results in the recognition and understanding of collective and subjective needs. Specifically, this would allow for the community to reinvigorate their secular values as a pillar of their collective identity, rejecting economic imperatives that would go against their meaning-making processes.

As a democratic procedure, Habermas (1984) points out that discourse in communicative action must be inclusive and transparent, allowing for all participants to have a say. In turn, this would also allow for the real needs of participants to be asserted and taken into account. As Fleming (2008) points out, communicative action would restore the critical balance by revitalizing "autonomous, 
self-organised public spheres that are capable of asserting themselves against the media of money and power" (p. 10). For Habermas (1987), the promise of communicative action may allow for processes to be set into motion which result in the decolonization of the lifeworld, inverting the balance in order to allow for meaning-making to guide the functioning of system activities. However, to trump the colonization and domination of zweckrationalität and the logic of capital, communicative action may need to go beyond the creation of spaces themselves.

\section{The colonization of higher education}

In his paper We are Condemned to Learn: Towards Higher Education as a Learning Society Fleming (2008) problematizes the current state of higher education. He discusses ways to reach a more critical discourse in the field through the uses of Habermasian notions and theories. Fleming (2008) goes along with perhaps one of the most fundamental principles of critical higher education discourse, warning of the "dangers of allowing unregulated free-market capitalism set the agenda for higher education" (p. 3). Above all, this discourse identifies the necessity to reconfigure pedagogical practices, address inequality in society, and enhance social inclusion. Interpreting Habermas, Fleming (2008) argues that the revitalization of civil society and the maintenance of a critical public sphere are tasks that must be taken up by a critical higher education. However, the current state of higher education gives only little space for critical, let alone reflective discourse.

The colonization of the lifeworld has spilled over into the realm of higher education, with the system's agenda and values dominating public discourse both within and outside of academic territory. In turn, this realizes itself in a variety of ways. Most notably, the functional imperatives of the economy have colonised the way in which actors in higher education are conceptualized: students are seen as consumers and teachers as providers. As such, their relation may no longer be seen as one of pedagogical interaction, but of commodified communication. Furthermore, Fleming (2008) argues that "everything is judged by money. The price of everything is measured and students become unit costs" (p. 7). This underscores the managerial treatment of education, where students are no longer seen as social actors but as both investment assets and consuming subjects. Beyond the re-conception of students and teachers in terms of system logics, Fleming (2008) points out the architectural and campus design: physical spaces, crucial for social interaction and conversation, have been replaced by commercial ventures, banks, and coffee shops, to mention but a few. Instead of having spaces 
to create a public sphere for dialogue, students and teachers are invited to consume to contribute to the economy; the physical space formerly used for deliberation and politicization is now taken over by the embodiment of system interests. The third aspect that Fleming (2008) points to is the role of e-learning and technology: the constant ability of teachers to centralize information and data about students' behaviour, and monitor and measure their interaction in an electronic panoptic. Students' behaviour and interactions become quantified, rendering them as merely analysable data (Fleming, 2008).

These three aspects mentioned by Fleming (2008) are by no means exhaustive, but serve to give a general account to the ways in which the lifeworld, in terms of higher education, has been colonised by capitalist imperatives and functioning. Rooted in the logic of capital, all these aspects embody the ways in which language itself has also been colonized by the system. From a Habermasian perspective, Fleming (2008) suggests the creation of spaces for communicative action as a learning project in higher education, which may serve to counteract and resist the colonization of the lifeworld. While this may seem like an important step towards building resistance against the hegemony of capital, it encounters one main and inexorable problem: language.

\section{Resisting the logic of capital beyond communicative action}

Both Fleming (2008) and Habermas (1984) point out the vital role of the public sphere in the project of de-colonizing the lifeworld. A critical higher education should therefore serve to foster the creation of spaces in the public realm where communicative action may occur. However, there is a challenged posed to the prescription of communicative action that both Habermas and Fleming ignore: the language-games used in these spaces to talk about certain topics and engage in discussion and deliberation. In the case of higher education, the language-games exercised have been invaded, or colonized, by the logic of capital. More precisely, the advent of modernity and the colonization of the lifeworld result in a very concise reality: capitalism oppresses the fundamental idea of critical higher education by determining the language-games that we use to talk about education.

First, however, it is necessary to outline the concept of language-games, as well as its relevance for the debate of critical higher education in our capitalist reality. Wittgenstein (1968) explains his notion of language games and meaning in an attempt to explore the role of language in the way we perceive the world. To him, every word that is spoken is part of a language-game: words and utterances 
are context-dependent on the game in which they find themselves. For instance, when I go to the shop and ask for the price of a 'block' of paper, the word 'block' acquires its meaning in the context of both the purchase as well as its capacity to describe the amount of paper to be bought. 'Block', however, may also refer to a neighbourhood or conglomeration of streets. Even though the physical utterance may remain the same, the meaning of the precise word may change depending on how, where, and when it is uttered. Language is thus comprised of language-games, where a set of words are related insofar as they find themselves in the same context. Additionally, because language only has meaning in a specific context, we should not attempt to impose the rules of a certain language-game on another. This would subsequently pervert meaning and tarnish the use of language-games (Wittgenstein, 1968).

Wittgenstein's (1968) central thesis is that words in language-games are context dependent, leading their meaning to only be valid as part of a certain language-game. System notions, such as profitability, efficiency, and growth, are all part of a language-game that originates in the context of capitalist modernity. The colonization of the lifeworld brought about by capitalist modernization has effectively led to system notions such as profitability and efficiency displacing other interests, including meaning-making and communicative action, that are key to the nature of the lifeworld. It becomes clear that besides simply shifting, and in some cases eradicating lifeworld interests, the logic of capital embedded in the system imperatives has re-shaped the very meaning of the words we use when we speak about higher education.

As a space where meanings are constructed, where communication between actors occur, and where cultural knowledge is transmitted and even questioned, higher education represents perhaps one of the most intrinsically valuable spaces for the lifeworld. The crisis of higher education comes about as the functional imperatives of the system, with its agenda and discourse, usurp this realm. Alongside this, the colonization has brought with it the language-games used in the context of the system, crushing the language-games previously prevalent in higher education. Formerly, a specific type of language-game was used in the realm of higher education, primarily employed with the purpose of meaning-making, identity construction, and deliberation. The lifeworld colonization, first and foremost, has shifted away these language-games and replaced them with those rooted in the logic of capital.

There is a large variety of instances where this occurs. For example, we can take the re-conceptualization already pointed out by Fleming (2008) of students and teachers into consumers and providers. Imagine a situation that, though admittedly utopic, embodies Habermas' (1984) promise of communicative 
action: a group of students and teachers come together for an assembly, where they aim to discuss their curriculum. Let us imagine that during the conversation, where each participant is allowed to speak and therefore reveal his or her real needs, students and teachers begin to discuss the quality of a certain course; as an example, we may imagine this is an introductory course in philosophy. While it may be clear from the content of the conversation that the students wish for the curriculum to integrate more critical, non-western thinkers, the very way in which these demands are phrased show the deep effect of lifeworld colonization. Assertions such as 'I paid a lot of money and expect the quality to be better' or 'I have worked so hard to not get what I want out of the course' embody the trap of system language-games. In both cases, there is an allusion to the logic of capital: while on the one hand a participant expects for his or her monetary investment to be remunerated, on the other hand there is a similar expectation for education to be a productive force where labour is compensated accordingly. 'Paying a lot of money' or expecting to 'get what I want from working hard' are both conjectures that make part of system language-games, as they could be commonly used in conversations that occur in primarily economic contexts. What this shows, above all, is the way in which capitalist modernity traps the ability of higher education actors to disclose their needs and concerns in a way that is not mediated through a language-game founded on the logic of capital.

Beyond this particular example, there are other ways in which system logic has come to shape words that are used on a daily basis in the context of higher education. For instance, 'educational investment', from both state and non-state actors, has become merely focused on enhancing the university's ability to create output in terms of human capital for the labour market. Investing in education, therefore, acquires a purpose that goes beyond the sphere of universities themselves. In this case, while it may directly relate to building better facilities or hiring 'better' teaching staff, the need for investment comes from the extrinsic necessity to accommodate to the needs of the labour market and consequently the economy. In a setup of communicative action, participants may consensually agree that there needs to be more significant funding for universities. However, the trap lies in the idea that calling for the increase of investment may fulfil a purpose that goes even beyond the needs they thought they were expressing: even if teachers and students believe investment could be conducive to enhancing their abilities to create and build a thriving critical education, it may instead result merely in the further marketization of universities and academic institutions. The impossibility of a critical discourse in higher education arises from the fact that capitalist modernity does not allow for the expression of language-games different to those of the system. The promise of communicative action finds itself 
crushed at our inability to crawl out of the cage that the lifeworld colonization has created in our language; but in this scenario, what can be done to pursue the ideal of a critical higher education?

First, a way must be found to change the language-games that we use when speaking about higher education. It is upon this foundation that a critical discourse could be built, undisrupted by system logics. The methods through which this could be achieved are numerous: higher education institutions could attempt to consciously employ words and language-games that are not directly related to the logic of capital, or that even allow for challenging this logic. For instance, this may include the case of 'educational investment' previously mentioned. In addition, grassroots movements that advocate for an increase in spaces for political debate and deliberation could likewise attempt to consciously frame their discourse by means of language-games that are not fundamentally tied to system logics. Evidently, this shows that a possibility may arise from both a topdown institutional approach, as well as from a bottom-up grassroots initiative. However, parallel to creating spaces and opportunities for these language-games to be subverted, there must be an effort from a plurality of higher education actors to point out and lay bare the deep entrenching and establishing of the logic of capital into the ways that we talk about education. Bringing to light the strength with which our language-games are embedded into the system will allow not only for the formulation of a critique of this ever-growing occurrence, but also for the development of linguistic tools to counteract it. In face of what seems to be an inevitable trap posed by capitalist modernity against critical discourse, subversive and critical movements in, around, and beyond educational institutions must take up as their main cause the blatant exposure of the deeply rooted logic of capital in the way we talk and conceive of higher education.

\section{Conclusion}

This paper argued that that if we want to strive for a critical higher education we must move beyond creating spaces for communicative action, instead reflecting upon the language-games that we use when we speak about education. By first exposing and reflecting upon the language-games that we use when we speak about higher education, we can acquire the tools to articulate a critical discourse. In order to reach this conclusion, the paper pointed to Habermas' (1984; 1987) and Wittgenstein's (1968) theories on the colonization of the lifeworld and communicative action, and language-games respectively. In conjunction to this, it outlined the account of the current crisis in higher education as described by 
Fleming (2008). Finally, it explained the challenge posed to the prescription of communicative action in the realm of higher education: the colonization of the lifeworld has also lead to the invasion of language-games originated in the system. Taking this into account, we must create different discourses about higher education where we are not constricted to the current language-games determined by the logic of capital. This process may be carried out in a variety of ways, originating from an institutional reform of language or from grassroots student movements attempting to 'think outside the box'. In any case, in order to alleviate the crisis that higher education has succumbed to as a result of capitalist modernization, we must be critical about the language that we use before we are able to start acting; if we want to change the world, we may have to do it one word at a time.

\section{References}

Bolton, R. (2005). Habermas's theory of communicative action and the theory of social capital, presented at the Association of American Geographers, Denver, Colorado, April 2005. Williamstown, MA: Williams College Press. Retrieved from https://pdfs.semanticscholar. org/4d37/9047laaf0ea2280aa70165lec97ba920934d.pdf

Fleming, T. (2008). We are condemned to learn: Towards a higher education as a learning society. Level 3, (6), 1-18. Retrieved from http://eprints.maynoothuniversity.ie/1053/1/ WeArecondemnedToLearnTFleming.pdf

Habermas, J. (1984). Relations to the world and aspects of rationality in four sociological concepts of action. In T. McCarthy (Trans.), The theory of communicative action: Vol. 1, reason and the rationalization of society (p. 75-102). Boston, MA: Beacon Press.

Habermas, J. (1987). Immediate reflections: System and lifeworld. In T. McCarthy (Trans.), The theory of communicative action: Vol. 2, lifeworld and system: A critique of functionalist reason (p. 113199). Boston, MA: Beacon Press.

Marx, K., \& Engels, F. (1969). Manifesto of the Communist Party. In Karl Marx and Friederick Engels Selected Works (p. 98-137). Moscow: Progress Publishers.

Sloan, T. S. (1999). The colonization of the lifeworld and the destruction of meaning. Radical Psychology, 1(2). Retrieved from http://www.radpsynet.org/journal/voll-2/Sloan.html

Wittgenstein, L. (1968). Philosophical investigations. Wittgenstein. New York, NY: Macmillan. (Original work published in 1953). 